\title{
Genetic variants in MIR17HG affect the susceptibility and prognosis of glioma in a Chinese Han population
}

\author{
Jigao Feng ${ }^{\dagger}$, Yibin Ouyang ${ }^{\dagger}$, Dedong Xu, Qinglong He, Dayuan Liu, Xudong Fan, Pengxiang Xu and Yehe Mo*
}

\begin{abstract}
Background: IncRNA MIR17HG was upregulated in glioma, and participated in promoting proliferation, migration and invasion of glioma. However, the role of MIR17HG polymorphisms in the occurrence and prognosis of glioma is still unclear.

Methods: In the study, 592 glioma patients and 502 control subjects were recruited. Agena MassARRAY platform was used to detect the genotype of MIR17HG polymorphisms. Logistic regression analysis was used to evaluate the relationship between MIR17HG single nucleotide polymorphisms (SNPs) and glioma risk by odds ratio (OR) and 95\% confidence intervals (Cls). Kaplan-Meier curves, Cox hazards models were performed for assessing the role of these SNPs in glioma prognosis by hazard ratios (HR) and 95\% Cls.

Results: We found that rs7318578 ( $\left.\mathrm{OR}=2.25, p=3.18 \times 10^{-5}\right)$ was significantly associated with glioma susceptibility in the overall participants. In the subgroup with age $<40$ years, rs $17735387\left(\mathrm{OR}=1.53, p=9.05 \times 10^{-3}\right)$ and rs7336610 $(\mathrm{OR}=1.35$, $p=0.016)$ were related to the higher glioma susceptibility. More importantly, rs17735387 ( $H R=0.82, \log$-rank $p=0.026)$ were associated with the longer survival of glioma patients. The GA genotype of rs17735387 had a better overall survival (HR=0.75, $\log$-rank $p=0.013)$ and progression free survival $(H R=0.73, \log$-rank $p=0.032)$ in patients with $1-I$ glioma. We also found that rs72640334 was related to the poor prognosis ( $H R=1.49$, Log-rank $p=0.035)$ in female patients. In the subgroup of patients with age $\geq 40$ years, rs 17735387 was associated with a better prognosis ( $H R=0.036$, Log-rank $p=0.002$ ).

Conclusion: Our study firstly reported that MIR17HG rs7318578 was a risk factor for glioma susceptibility and rs17735387 was associated with the longer survival of glioma among Chinese Han population, which might help to enhance the understanding of MIR17HG gene in gliomagenesis. In subsequent studies, we will continue to collect samples and follow up to further validate our findings and further explore the function of these MIR17HG SNPs in glioma in a larger sample size.
\end{abstract}

Keywords: Glioma, MIR17HG, Genetic variants, Susceptibility, Prognosis

\section{Background}

Glioma is the most frequent neoplasms originated from neuroglial stem or progenitor cells, accounting for $80 \%$ of primary malignant brain cancers with approximately 101, 600 individuals diagnosed in China each year [1, 2]. Despite

\footnotetext{
*Correspondence: xdd8617@163.com

${ }^{\dagger}$ Jigao Feng and Yibin Ouyang are co-first authors.

Department of Neurosurgery, the Second Affiliated Hospital of Hainan

Medical University, \#48 Baishuitang Road, Haikou 570311, Hainan, China
}

the efforts of diagnosis and therapeutics, the prognosis of glioma is still depressing. Until now, the aetiology of glioma remains unclear. However, environmental and occupational exposures have been identified to be associated with the occurrence and development of glioma, especially highdosage ionizing radiation [3]. In addition, genetic factors are also given a pivotal contribution to the occurrence and prognosis of glioma [4-6]. Several association studies have

C C The Author(s). 2020 Open Access This article is licensed under a Creative Commons Attribution 4.0 International License, which permits use, sharing, adaptation, distribution and reproduction in any medium or format, as long as you give appropriate credit to the original author(s) and the source, provide a link to the Creative Commons licence, and indicate if changes were made. The images or other third party material in this article are included in the article's Creative Commons licence, unless indicated otherwise in a credit line to the material. If material is not included in the article's Creative Commons licence and your intended use is not permitted by statutory regulation or exceeds the permitted use, you will need to obtain permission directly from the copyright holder. To view a copy of this licence, visit http://creativecommons.org/licenses/by/4.0/ The Creative Commons Public Domain Dedication waiver (http://creativecommons.org/publicdomain/zero/1.0/) applies to the data made available in this article, unless otherwise stated in a credit line to the data. 
revealed that single nucleotide polymorphisms (SNPs) were associated with glioma risk and survival [7-9].

MIR17HG gene, located on chromosome 13q31.3, is the host gene of the microRNA 17-92 cluster. Functional studies have confirmed that the MIR17HG gene might be related to cell survival, proliferation, differentiation, and angiogenesis [10]. LncRNA MIR17HG, also as a long noncoding RNA which regulating the expression of miRNA, played a carcinogenic effect in various cancers including rectal cancer, gastric cancer, and lung cancer [11-13]. A recent research showed that lncRNA MIR17HG was overexpressed in glioma, and lncRNA MIR17HG knockdown inhibited the proliferation, migration and invasion of glioma, suggesting that lncRNA MIR17HG might facilitate the malignant progress of glioma [14]. Recently, increasing evidences indicated that genetic polymorphisms of MIR17HG were associated with the occurrence of multiple tumors, such as lymphoma, colorectal cancer, breast cancer [15-17]. However, the role of MIR17HG variants in glioma occurrence and prognosis is still unclear.

Here, we analyzed the association of selected MIR17HG SNPs and glioma susceptibility among the Chinese Han population, and examined the possible role of these polymorphisms in different glioma subgroups stratified by age, gender and grade. We also evaluated the influence of MIR17HG genetic variants on the survival of glioma patients.

\section{Methods}

\section{Subjects}

This study recruited 592 glioma patients and 502 control subjects. All participants were genetically unrelated Chinese Han population. Glioma patients who diagnosed and confirmed by histopathology were enrolled from the department of Neurosurgery at Tangdu Hospital from February 2014 to March 2018. Patients with history of cancer and other systemic or complex diseases were excluded. Age- and gender-matched healthy controls were recruited from the physical examination center of the hospital. The controls were free from any cancer and any disease related to brain and central nervous system. Standardized questionnaires and medical records were used to collect demographic and clinical information. The follow-up information was obtained by telephone and return visit every 3 months; and the survival time, progress and outcome were recorded. After, approximately $5 \mathrm{~mL}$ blood samples were collected for further analysis. Our study was approved by the Ethics Committee of the Second Affiliated Hospital of Hainan Medical University and was in the Declaration of Helsinki. Written informed consent was obtained from each participant.

\section{Genotyping}

Genomic DNA was purified by a commercially available GoldMag DNA Purification Kit (GoldMag Co. Ltd., Xi' an City, China). NanoDrop 2000 (Thermo Scientifc, Waltham, MA, USA) was used to check DNA quality. Five MIR17HG SNPs (rs17735387, rs72640334, rs7318578, rs7336610, and rs75267932) were identified based on the NCBI dbSNP database, the 1000 Genomes Project data with minor allele frequencies (MAFs) $>5 \%$ in Chinese Han Beijing (CHB) population and Haploview software with a pairwise linkage disequilibrium $\left(\mathrm{r}^{2}>0.80\right)$. MIR17HG polymorphisms were genotyped using Agena MassARRAY platform (Agena, San Diego, CA, U.S.A.) as previously described [18]. The primers sequences were presented in Supplementary Table 1. Genotyping was in a blinded manner, and the call rate was $\geq 0.99$. For quality control, $10 \%$ of blind and random samples were repeated genotyping, and the result was $100 \%$ reproducibility.

\section{Data analysis}

Statistical analysis were performed using SPSS version 18.0 (SPSS Inc., Chicago, IL, USA) and PLINK 2.1.7 package. The Chi square test or Student's t-test was carried out to compare the differences in age and gender distributions between patients and controls, as appropriate. Hardy-Weinberg equilibrium (HWE) was performed for the controls using goodness-of-fit $x^{2}$ test. Logistic regression analysis was used to analyze the genetic effects of MIR17HG SNPs on the risk of glioma by calculating odds ratio (OR) and 95\% confidence intervals (CIs) adjusted for age and sex. Multiple testing correction was performed by the false discovery (FDR). The overall survival (OS) and progression-free survival (PFS) of glioma patients were plotted by Kaplan-Meier survival curves. Univariate and multivariate Cox proportional hazards models were performed to assess the role of MIR17HG polymorphisms in the prognosis of glioma by calculating hazard ratio (HR) and 95\% CIs. A twotailed $p$ value of $<0.05$ was statistically significant.

\section{Results \\ Participants' features}

The characteristics of patients and controls were presented in Table 1. The case group consisted of 592 glioma patients ( $40.53 \pm 13.90$ years, $55.1 \%$ males) and 502 healthy controls ( $40.46 \pm 18.08$ years, $54.8 \%$ males). The frequency distribution of age $(p=0.934)$ and sex $(p=0.924)$ between cases and controls were no statistical differences. Among the cases, there were 378 patients with WHO 2007 grade I + II and 214 patients with grade III + IV .

\section{The genotyping results of MIR17HG variants}

Five SNPs in MIR17HG were genotyped to determine the possible effect of MIR17HG variants on the risk or prognosis of glioma. The minor allele frequencies in patients and controls were displayed in Supplementary Table 2. The genotype frequencies of all the studied variants in the 
Table 1 Characteristics of patients with glioma and health controls

\begin{tabular}{|c|c|c|c|}
\hline Characteristics & Cases $(n=592)$ & Controls $(n=502)$ & $p$ \\
\hline Age (Mean $\pm S D$, years) & $40.53 \pm 13.90$ & $40.46 \pm 18.08$ & $0.934^{a}$ \\
\hline Gender (Males/Females) & $326 / 266$ & $275 / 227$ & $0.924^{b}$ \\
\hline \multicolumn{4}{|l|}{ WHO grade } \\
\hline । & 43 & & \\
\hline$\|$ & 335 & & \\
\hline$\|$ & 149 & & \\
\hline IV & 65 & & \\
\hline \multicolumn{4}{|l|}{ Surgical method } \\
\hline STR & 177 & & \\
\hline NTR & 8 & & \\
\hline GTR & 407 & & \\
\hline \multicolumn{4}{|l|}{ Radiotherapy } \\
\hline No & 58 & & \\
\hline Conformal radiotherapy & 159 & & \\
\hline Gamma knife & 375 & & \\
\hline \multicolumn{4}{|l|}{ Chemotherapy } \\
\hline No & 349 & & \\
\hline Yes & 243 & & \\
\hline \multicolumn{4}{|l|}{ Survival condition } \\
\hline Survival & 41 & & \\
\hline Lost to follow-up & 24 & & \\
\hline Death & 527 & & \\
\hline
\end{tabular}

Abbreviations: WHO World Health Organization, NTR Near-total resection, STR Sub-total resection, GTR Gross-total resection

a $p$ values was calculated by independent samples $T$ test

${ }^{b} p$ values was calculated by Chi-square tests

control group were in HWE $(p>0.05)$, and the genotyping rate exceeded $99.5 \%$.

The correlation between MIR17HG variants and glioma risk The genotype and allele frequencies of these SNPs in MIR17HG were displayed in Table 2. Compared with the control group, the frequencies of $\mathrm{C}$ allele $(34.9 \%$ vs $28.9 \%$ ) and CC genotype (19.7\% vs $9.0 \%$ ) of rs7318578 were higher in glioma patients. In details, rs7318578 C allele $\left(\mathrm{OR}=1.32\right.$, 95\% CI: $\left.1.10-1.58, p=2.63 \times 10^{-3}\right)$ and $\mathrm{CC}$ genotype $(\mathrm{OR}=2.25,95 \% \mathrm{CI}: 1.54-3.31, p=3.18 \times$ $10^{-5}$ ) were related to the increased glioma susceptibility compared with the A allele and AA genotype, respectively, and the significance still existed after the FDR controlling procedure (FDR- $p=0.032$ and FDR- $p=0.001$ respectively). Moreover, rs7318578 variant showed a 1.26-fold increased risk of glioma under the additive model $\left(\mathrm{OR}=1.26,95 \% \mathrm{CI}: 1.07-1.49, p=6.23 \times 10^{-3}\right)$. There was no association between other SNPs and the risk of glioma.

We further explored the association between glioma risk and MIR17HG SNPs by stratifying for age, sex and WHO grade. Among subjects of age $\geq 40$ years, carriers with rs7318578 CC genotype showed a 2.46-fold increased the susceptibility to glioma compared with individuals with the AA genotype (OR $=2.46$, 95\% CI: $1.42-$ $4.28, p=1.41 \times 10^{-3}$, FDR- $p=0.035$, Table 3$)$. Additionally, rs17735387 was a risk factor for glioma occurrence: A vs $\mathrm{G}: \mathrm{OR}=1.53,95 \% \mathrm{CI}: 1.11-2.11, p=9.05 \times 10^{-3}$; AA vs $G G:$ OR $=3.27,95 \%$ CI: $1.09-9.80, p=0.034$; $\mathrm{GA}+\mathrm{AA}$ vs $\mathrm{GG}: \mathrm{OR}=1.57,95 \% \mathrm{CI}: 1.07-2.30, p=$ 0.021 ; additive: $\mathrm{OR}=1.56,95 \% \mathrm{CI}: 1.12-2.18, p=8.55 \times$ $10^{-3}$ at age $<40$ years. MIR17HG rs7318578 C allele $(\mathrm{OR}=1.37,95 \% \mathrm{CI}: 1.05-1.79, p=0.020)$ and $\mathrm{CC}$ genotype $(\mathrm{OR}=1.88,95 \% \mathrm{CI}: 1.08-3.28, p=0.026)$ was associated with the increased risk of glioma in subjects aged younger 40 years. Results of multiple models showed that rs7336610 was associated with the high glioma susceptibility at age $<40$ years $(\mathrm{C}$ vs $\mathrm{T}$ : $\mathrm{OR}=1.35,95 \%$ CI: $1.06-1.73, p=0.016$; TC vs TT: $\mathrm{OR}=1.56,95 \% \mathrm{CI}$ : $1.02-2.39, p=0.041 ; \mathrm{CC}$ vs TT: $\mathrm{OR}=1.72,95 \% \mathrm{CI}$ : $1.02-2.92, p=0.044 ; \mathrm{TC}+\mathrm{CC}$ vs TT: $\mathrm{OR}=1.61,95 \% \mathrm{CI}$ : $1.07-2.41, p=0.022$; additive: $\mathrm{OR}=1.33$, 95\% CI: $1.02-$ $1.73, p=0.034)$.

Stratified by gender (Table 3), the significant association between rs7318578 and the glioma of risk was observed in 
Table 2 The effect of MIR17HG variants on the risk of glioma

\begin{tabular}{|c|c|c|c|c|c|c|}
\hline SNP ID & Allele/Genotype & Control & Case & OR (95\% Cl) & $p$ & FDR- $p$ \\
\hline \multirow[t]{7}{*}{ rs17735387 } & G & 829 & 964 & 1 & & \\
\hline & A & 175 & 220 & $1.08(0.87-1.35)$ & 0.486 & 0.778 \\
\hline & GG & 341 & 395 & 1 & & \\
\hline & GA & 147 & 174 & $1.02(0.79-1.33)$ & 0.871 & 0.909 \\
\hline & AA & 14 & 23 & $1.42(0.72-2.80)$ & 0.315 & 0.756 \\
\hline & $\mathrm{GA}+\mathrm{AA}$ & 161 & 197 & $1.06(0.82-1.36)$ & 0.672 & 0.806 \\
\hline & Additive & / & / & $1.08(0.87-1.34)$ & 0.488 & 0.732 \\
\hline \multirow[t]{7}{*}{ rs72640334 } & C & 916 & 1070 & 1 & & \\
\hline & $A$ & 86 & 110 & $1.10(0.81-1.47)$ & 0.547 & 0.772 \\
\hline & $\mathrm{CC}$ & 418 & 487 & 1 & & \\
\hline & CA & 80 & 96 & $1.03(0.74-1.43)$ & 0.860 & 0.938 \\
\hline & AA & 3 & 7 & $2.01(0.51-7.83)$ & 0.316 & 0.689 \\
\hline & $C A+A A$ & 83 & 103 & $1.07(0.78-1.46)$ & 0.696 & 0.795 \\
\hline & Additive & / & / & $1.09(0.82-1.47)$ & 0.550 & 0.733 \\
\hline \multirow[t]{7}{*}{ rs7318578 } & A & 714 & 768 & 1 & & \\
\hline & C & 290 & 412 & $1.32(1.10-1.58)$ & $2.63 \times 10^{-3}$ & 0.032 \\
\hline & $\mathrm{AA}$ & 257 & 294 & 1 & & \\
\hline & $A C$ & 200 & 180 & $0.79(0.61-1.02)$ & 0.073 & 0.438 \\
\hline & $C C$ & 45 & 116 & $2.25(1.54-3.31)$ & $3.18 \times 10^{-5^{*}}$ & 0.001 \\
\hline & $A C+C C$ & 245 & 296 & $1.06(0.83-1.34)$ & 0.654 & 0.826 \\
\hline & Additive & / & / & $1.26(1.07-1.49)$ & $6.23 \times 10^{-3}$ & 0.050 \\
\hline \multirow[t]{7}{*}{ rs7336610 } & T & 527 & 602 & 1 & & \\
\hline & C & 475 & 580 & $1.07(0.90-1.27)$ & 0.438 & 0.809 \\
\hline & $\pi$ & 141 & 144 & 1 & & \\
\hline & $\mathrm{TC}$ & 245 & 314 & $1.26(0.94-1.67)$ & 0.119 & 0.476 \\
\hline & CC & 115 & 133 & $1.13(0.80-1.59)$ & 0.477 & 0.818 \\
\hline & $\mathrm{TC}+\mathrm{CC}$ & 360 & 447 & $1.22(0.93-1.59)$ & 0.157 & 0.419 \\
\hline & Additive & / & / & $1.07(0.90-1.27)$ & 0.433 & 0.866 \\
\hline \multirow[t]{7}{*}{ rs75267932 } & $A$ & 879 & 1061 & 1 & & \\
\hline & G & 125 & 123 & $0.82(0.63-1.06)$ & 0.130 & 0.446 \\
\hline & $\mathrm{AA}$ & 385 & 479 & 1 & & \\
\hline & $A G$ & 109 & 103 & $0.76(0.56-1.03)$ & 0.073 & 0.438 \\
\hline & GG & 8 & 10 & $1.01(0.39-2.58)$ & 0.988 & 0.988 \\
\hline & $A G+G G$ & 117 & 113 & $0.78(0.58-1.04)$ & 0.089 & 0.427 \\
\hline & Additive & I & / & $0.82(0.63-1.07)$ & 0.138 & 0.414 \\
\hline
\end{tabular}

Abbreviations: SNP Single nucleotide polymorphism, OR Odds ratio, CI Confidence interval, FDR False discovery

$p$ values were calculated by logistic regression analysis with adjustments for age and gender

Bold $p<0.05$ means the data is statistically significant

* After Bonferroni correction $[p<0.05 /(5 \times 4)]$ means the data is statistically significant

males (CC vs AA: OR $=1.80,95 \%$ CI: $1.10-2.95, p=$ $0.020)$ and females (CC vs AA: $\mathrm{OR}=3.08,95 \% \mathrm{CI}: 1.67-$ 5.67, $p=3.19 \times 10^{-4}$, FDR- $p=0.046$ and additive: $\mathrm{OR}=$ 1.43, $95 \%$ CI: $1.11-1.84, p=5.96 \times 10^{-3}$ ). Especially, the association under the allele model in females was still significant $(\mathrm{C}$ vs $\mathrm{A}: \mathrm{OR}=1.53,95 \% \mathrm{CI}: 1.16-2.01, p=2.49 \times$ $10^{-3}$, FDR- $p=0.029$ ).
In the stratified analysis by WHO grade, rs7336610 showed a genotype difference between patients with grade III-IV and patients with grade I-II, with OR from 1.31 to 1.72 (TC vs TT: $\mathrm{OR}=1.58,95 \% \mathrm{CI}: 1.02-2.43, p=0.039$; $\mathrm{CC}$ vs TT: $\mathrm{OR}=1.72,95 \% \mathrm{CI}: 1.04-2.86, p=0.036 ; \mathrm{TC}+\mathrm{CC}$ vs TT: $\mathrm{OR}=1.62,95 \%$ CI: $1.07-2.45, p=0.022$; and additive: $\mathrm{OR}=$ 1.31, 95\% CI: $1.02-1.68, p=0.035$ ), as shown in Table 4. 
Table 3 The effect of MIR17HG variants on the risk of glioma stratified by age and gender

\begin{tabular}{|c|c|c|c|c|c|c|c|}
\hline SNP ID & Allele/Genotype & OR (95\% Cl) & $p$ & FDR- $p$ & OR $(95 \% \mathrm{Cl})$ & $p$ & FDR- $p$ \\
\hline Age (year) & & $\geq 40$ & & & $<40$ & & \\
\hline \multirow[t]{7}{*}{ rs17735387 } & G & 1 & & & 1 & & \\
\hline & A & $0.79(0.59-1.07)$ & 0.128 & 0.400 & $1.53(1.11-2.11)$ & $9.05 \times 10^{-3}$ & 0.109 \\
\hline & GG & 1 & & & 1 & & \\
\hline & GA & $0.73(0.51-1.05)$ & 0.093 & 0.465 & $1.45(0.98-2.16)$ & 0.065 & 0.142 \\
\hline & AA & $0.87(0.35-2.16)$ & 0.765 & 0.911 & $3.27(1.09-9.80)$ & 0.034 & \\
\hline & $G A+A A$ & $0.74(0.52-1.06)$ & 0.101 & 0.421 & $1.57(1.07-2.30)$ & 0.021 & 0.101 \\
\hline & Additive & $0.80(0.59-1.08)$ & 0.152 & 0.380 & $1.56(1.12-2.18)$ & $8.55 \times 10^{-3}$ & 0.205 \\
\hline \multirow[t]{7}{*}{ rs7318578 } & A & 1 & & & 1 & & \\
\hline & C & $1.27(0.99-1.62)$ & 0.063 & 0.525 & $1.37(1.05-1.79)$ & 0.020 & 0.120 \\
\hline & AA & 1 & & & 1 & & \\
\hline & $A C$ & $0.64(0.44-1.02)$ & 0.051 & 0.188 & $0.94(0.63-1.40)$ & 0.754 & 0.952 \\
\hline & CC & $2.46(1.42-4.28)$ & $1.41 \times 10^{-3^{*}}$ & 0.035 & $1.88(1.08-3.28)$ & 0.026 & 0.089 \\
\hline & $A C+C C$ & $0.92(0.66-1.28)$ & 0.606 & 0.947 & $1.15(0.80-1.64)$ & 0.459 & 0.648 \\
\hline & Additive & $1.22(0.97-1.54)$ & 0.087 & 0.544 & $1.24(0.97-1.60)$ & 0.092 & 0.170 \\
\hline \multirow[t]{7}{*}{ rs7336610 } & T & 1 & & & 1 & & \\
\hline & C & $1.17(0.93-1.48)$ & 0.184 & 0.418 & $1.35(1.06-1.73)$ & 0.016 & 0.128 \\
\hline & $\pi$ & 1 & & & 1 & & \\
\hline & TC & $1.35(0.90-2.03)$ & 0.144 & 0.400 & $1.56(1.02-2.39)$ & 0.041 & 0.109 \\
\hline & CC & $1.35(0.84-2.16)$ & 0.210 & 0.438 & $1.72(1.02-2.92)$ & 0.044 & 0.106 \\
\hline & $\mathrm{TC}+\mathrm{CC}$ & $1.35(0.92-1.98)$ & 0.123 & 0.439 & $1.61(1.07-2.41)$ & 0.022 & 0.088 \\
\hline & Additive & $1.16(0.92-1.47)$ & 0.213 & 0.410 & $1.33(1.02-1.73)$ & 0.034 & 0.102 \\
\hline Gender & & Male & & & Female & & \\
\hline \multirow[t]{7}{*}{ rs7318578 } & A & 1 & & & 1 & & \\
\hline & C & $1.18(0.93-1.50)$ & 0.183 & 0.488 & $1.53(1.16-2.01)$ & $2.49 \times 10^{-3^{*}}$ & 0.029 \\
\hline & AA & 1 & & & 1 & & \\
\hline & $A C$ & $0.70(0.49-1.05)$ & 0.054 & 0.588 & $0.90(0.61-1.33)$ & 0.606 & 0.007 \\
\hline & $C C$ & $1.80(1.10-2.95)$ & 0.020 & 0.480 & $3.08(1.67-5.67)$ & $3.19 \times 10^{-4^{*}}$ & 0.871 \\
\hline & $A C+C C$ & $0.93(0.67-1.28)$ & 0.635 & 0.802 & $1.24(0.87-1.77)$ & 0.234 & 0.769 \\
\hline & Additive & $1.15(0.92-1.43)$ & 0.226 & 0.493 & $1.43(1.11-1.84)$ & $5.96 \times 10^{-3}$ & 0.046 \\
\hline
\end{tabular}

Abbreviations: SNP Single nucleotide polymorphism, OR Odds ratio, $\mathrm{Cl}$ Confidence interval, FDR False discovery

$p$ values were calculated by logistic regression analysis with adjustments for age and gender

Bold $p<0.05$ means the data is statistically significant

* After Bonferroni correction $[p<0.05 /(5 \times 4)]$ means the data is statistically significant

Table 4 The effect of MIR17HG variants on WHO grade of glioma

\begin{tabular}{|c|c|c|c|c|c|c|}
\hline SNP ID & Allele/Genotype & I-II & III-IV & OR $(95 \% \mathrm{CI})$ & $p$ & FDR- $p$ \\
\hline \multirow[t]{7}{*}{ rs7336610 } & $T$ & 400 & 202 & 1 & & \\
\hline & C & 354 & 226 & $1.26(1.00-1.60)$ & 0.053 & 0.221 \\
\hline & $\pi$ & 103 & 41 & 1 & & \\
\hline & $\mathrm{TC}$ & 194 & 120 & $1.58(1.02-2.43)$ & 0.039 & 0.244 \\
\hline & $C C$ & 80 & 53 & $1.72(1.04-2.86)$ & 0.036 & 0.300 \\
\hline & $\mathrm{TC}+\mathrm{CC}$ & 274 & 173 & $1.62(1.07-2.45)$ & 0.022 & 0.550 \\
\hline & Additive & / & / & $1.31(1.02-1.68)$ & 0.035 & 0.438 \\
\hline
\end{tabular}

Abbreviations: SNP Single nucleotide polymorphism, OR Odds ratio, Cl Confidence interval, FDR False discovery $p$ values were calculated by logistic regression analysis with adjustments for age and gender

Bold $p<0.05$ means the data is statistically significant 


\section{The correlation between MIR17HG variants and glioma prognosis}

In this study, 592 patients had complete follow-up data. The detail information for the follow-up was as following: the median, min and max follow-up time were 11 months, 2 months and 8 months, respectively. The median time to events for OS and PFS were 11 months and 8 months, respectively; total number of events for OS and DFS were 527 patients and 523 patients, respectively.

Next, we investigated the correlation between MIR17HG variants and PFS or OS of glioma by Kaplan-Meier survival method, univariate and multivariate Cox proportional hazard model. Rs17735387 was related to the PFS of glioma (Logrank $p=0.026$ ), as shown in Fig. 1 and Table 5. Multivariate Cox proportional hazard mode adjusted for age, sex WHO grade, surgical method, use of radiotherapy and chemotherapy showed that carriers of rs17735387 GA genotype might present a longer PFS than patients with GG genotype (HR = 0.82, 95\% CI: $0.68-0.99, p=0.042$; Table 6). No statistically significant association was found between other MIR17HG polymorphisms and the prognosis of glioma.

In patients with low-grade glioma (I-II), the KaplanMeier method (Table 5) revealed the association between MIR17HG rs17735387 and OS (Log-rank $p=0.032$, Fig. 2a) or PFS (Log-rank $p=0.013$, Fig. 2b). Univariate Cox proportional hazard model presented that the GA genotype of rs17735387 might had a better OS ( $\mathrm{HR}=0.77, p=0.042)$ and PFS $(\mathrm{HR}=0.75, p=0.024)$ when compared with GG genotype among patients with I-II glioma (Table 6). Moreover, the multivariate Cox proportional hazard model also displayed that a better prognosis for glioma was also seen for rs17735387-GA genotype (OS: $\mathrm{HR}=0.75, p=0.024$ and PFS: $\quad H R=0.73, \quad p=0.016)$. However, no association between MIR17HG polymorphisms and the prognosis of glioma in high-grade glioma patients was found.

The age and sex stratified analyses were performed to assess the association between MIR17HG polymorphisms and the prognosis of glioma. In female patients, KaplanMeier method (Table 5) revealed the association of rs72640334 with OS (Log-rank $p=0.035$, Fig. 2c) or PFS (Log-rank $p=0.049$, Fig. 2d). The results of univariate Cox proportional hazard model showed that rs72640334 was related to the poor prognosis $(\mathrm{OS}, \mathrm{HR}=1.49, p=0.027$ and PFS, $\mathrm{HR}=1.48, p=0.034$, Table 6). Kaplan-Meier method (Table 5) revealed the association between rs17735387 and OS (Log-rank $p=0.002$, Fig. 2e) or PFS (Log-rank $p=$ 0.002 , Fig. 2f) among patients with age $\geq 40$ years. In the subgroup of patients with age $\geq 40$ years, GA genotype (multivariate: $\mathrm{OS}, \mathrm{HR}=0.77, p=0.047$ ) and AA (univariate: PFS, HR =0.036, $p=0.007$; multivariate: OS, $\mathrm{HR}=0.46, p=$ 0.049 and PFS, HR $=0.45, p=0.042$, Table 6) genotype of rs17735387 were associated with a better prognosis.

\section{Discussion}

This study explored the possible relationship between MIR17HG variants and the occurrence and prognosis of glioma in a Chinese Han population. Our data revealed that rs7318578, rs17735387 and rs7336610 polymorphisms were associated with the increased susceptibility to glioma. We also found that rs17735387 was related to a better prognosis of patients with glioma. To our knowledge, we firstly reported that MIR17HG polymorphisms might be related to glioma susceptibility and patients' survival.

MIR17HG gene is also called c13orf25 and Oncomir-1, which encodes a polycistronic miR-17-92 cluster encompassed six miRNAs (miR-17, miR-18a, miR-19a, miR-

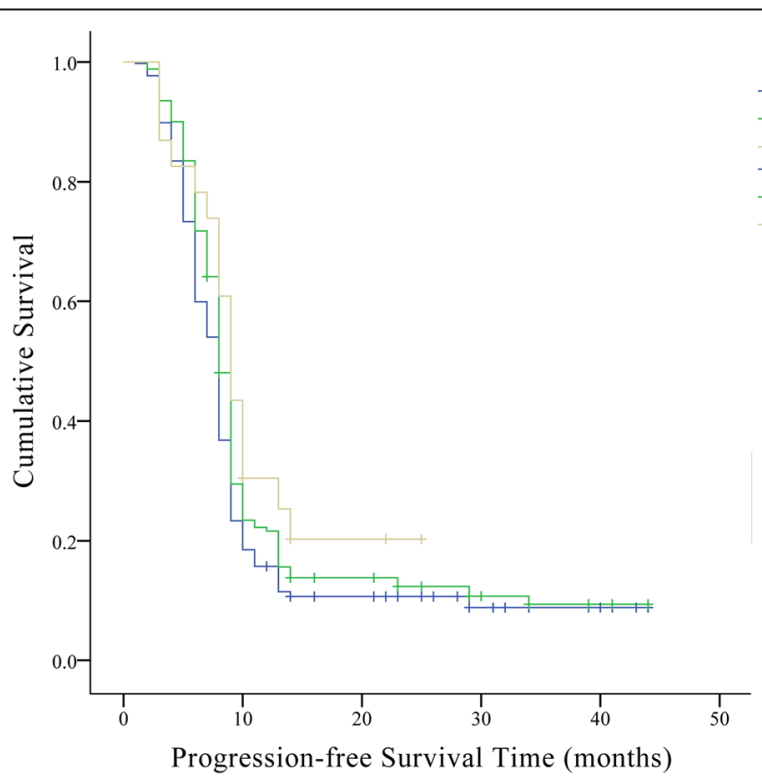

rs 17735387

$\neg \mathrm{GG}(\mathrm{n}=355)$

$\neg \mathrm{GA}(\mathrm{n}=150)$

$\mathrm{AA}(\mathrm{n}=18)$

+ GG-censored $(\mathrm{n}=39)$

+ GA-censored $(\mathrm{n}=20)$

AA-censored $(n=5)$

Fig. 1 Effect of MIR17HG rs17735387 on the survival of overall glioma patients 
Table 5 Kaplan-Meier analysis of the association between MIR17HG variants and OS and PFS of glioma patients

\begin{tabular}{|c|c|c|c|c|c|c|c|c|c|}
\hline \multirow[t]{2}{*}{ SNP ID } & \multirow[t]{2}{*}{ Genotype } & \multicolumn{4}{|l|}{ os } & \multicolumn{4}{|l|}{ PFS } \\
\hline & & Event/ Total & SR (1-/3-year) & MST (month) & Log-rank $p$ & Event/ Total & SR (1-/3-year) & MST (month) & Log-rank $p$ \\
\hline \multicolumn{10}{|l|}{ Overall } \\
\hline \multirow[t]{3}{*}{ rs17735387 } & GG & $356 / 395$ & $0.299 / 0.082$ & 11.0 & 0.070 & $355 / 394$ & $0.157 / 0.088$ & 8.0 & 0.026 \\
\hline & GA & $153 / 174$ & $0.360 / 0.101$ & 12.0 & & 150/170 & $0.216 / 0.094$ & 8.0 & \\
\hline & $A A$ & $18 / 23$ & $0.435 /-$ & 12.0 & & $18 / 23$ & $0.304 /-$ & 9.0 & \\
\hline \multirow[t]{3}{*}{ rs72640334 } & CC & $433 / 487$ & 0.319/0.092 & 11.0 & 0.365 & $430 / 483$ & $0.179 / 0.092$ & 8.0 & 0.470 \\
\hline & $C A$ & $86 / 96$ & $0.333 / 0.082$ & 10.0 & & $85 / 95$ & $0.179 / 0.093$ & 8.0 & \\
\hline & $A A$ & $7 / 7$ & $0.143 /-$ & 10.0 & & $7 / 7$ & $0.286 /-$ & 8.0 & \\
\hline \multirow[t]{3}{*}{ rs7318578 } & AA & $263 / 294$ & $0.335 / 0.085$ & 12.0 & 0.755 & $262 / 293$ & $0.192 / 0.083$ & 8.0 & 0.527 \\
\hline & $A C$ & $160 / 180$ & $0.306 / 0.093$ & 11.0 & & 159/178 & $0.163 / 0.097$ & 8.0 & \\
\hline & CC & $102 / 116$ & $0.319 / 0.111$ & 11.0 & & $101 / 115$ & $0.176 /-$ & 8.0 & \\
\hline \multirow[t]{3}{*}{ rs7336610 } & $\pi$ & $129 / 144$ & $0.326 / 0.095$ & 11.0 & 0.740 & $129 / 144$ & $0.174 / 0.096$ & 8.0 & 0.516 \\
\hline & $\mathrm{TC}$ & $281 / 314$ & $0.296 / 0.085$ & 11.0 & & $279 / 312$ & $0.167 / 0.089$ & 8.0 & \\
\hline & CC & $116 / 133$ & $0.381 / 0.095$ & 12.0 & & $114 / 130$ & $0.221 / 0.098$ & 8.0 & \\
\hline \multirow[t]{3}{*}{ rs75267932 } & AA & $425 / 479$ & $0.323 / 0.091$ & 11.0 & 0.766 & $422 / 475$ & $0.185 / 0.092$ & 8.0 & 0.634 \\
\hline & AG & $92 / 103$ & $0.311 / 0.095$ & 10.0 & & $91 / 102$ & $0.176 / 0.097$ & 8.0 & \\
\hline & GG & $10 / 10$ & $0.400 /-$ & 12.0 & & $10 / 10$ & $0.100 /-$ & 8.0 & \\
\hline \multicolumn{10}{|c|}{ Low-grade glioma (I-II) } \\
\hline \multirow[t]{3}{*}{ rs17735387 } & GG & $232 / 260$ & $0.292 / 0.090$ & 11.0 & 0.032 & $232 / 260$ & $0.158 / 0.093$ & 8.0 & 0.013 \\
\hline & GA & $86 / 102$ & 0.398/0.149 & 12.0 & & $84 / 100$ & $0.255 / 0.135$ & 9.0 & \\
\hline & AA & $12 / 16$ & $0.500 /-$ & 12.0 & & $12 / 16$ & $0.375 /-$ & 9.0 & \\
\hline \multicolumn{10}{|l|}{ Females } \\
\hline \multirow[t]{3}{*}{ rs72640334 } & $\mathrm{CC}$ & $196 / 221$ & $0.335 / 0.100$ & 12.0 & 0.035 & $195 / 219$ & $0.168 / 0.094$ & 8.0 & 0.049 \\
\hline & CA & $36 / 39$ & $0.205 /-$ & 9.0 & & $35 / 38$ & $0.105 /-$ & 6.0 & \\
\hline & AA & $6 / 6$ & $0.167 /-$ & 10.0 & & $6 / 6$ & $-/-$ & 8.0 & \\
\hline \multicolumn{10}{|l|}{ Age $\geq \mathbf{4 0}$ years } \\
\hline \multirow[t]{3}{*}{ rs17735387 } & GG & $217 / 232$ & $0.246 / 0.051$ & 10.0 & 0.002 & $216 / 231$ & $0.134 / 0.059$ & 8.0 & 0.002 \\
\hline & GA & $78 / 86$ & $0.360 / 0.081$ & 12.0 & & $78 / 86$ & $0.178 / 0.080$ & 8.0 & \\
\hline & AA & $7 / 11$ & $0.303 /-$ & 16.0 & & $7 / 11$ & 0.545 & 13.0 & \\
\hline
\end{tabular}

Abbreviations: OS Overall survival, PFS Progression free survival, SR Survival rate, MST Median survival time Log-rank $p$ values were calculated using the Chi-Square test Bold $p<0.05$ indicates statistical significance

20a, miR-19b-1, and miR-92a-1). The miR-17-92 cluster was deregulated in glioma, indicating that these miRNA played a key role of in gliomagenesis [19, 20]. Schulte JH et al. reported that miR-17-92 cluster amplification in neuroblastomas was associated with a poor prognosis [21]. IncRNA MIR17HG was upregulated in glioma tissues and cell lines, and acted as competing endogenous RNA (ceRNA) to sponge miR-346/miR-425-5p in regulating the malignant of glioma [14]. Yuze Cao et al. reported that IncRNA MIR17HG-mediated ceRNA network was identified as a potential prognostic biomarker for glioblastoma [22]. Moreover, Xue Leng et al. observed that MIR17HG was highly expressed in glioma and participated in piR-DQ590027/ lncRNA MIR17HG/ miR-153(miR-377)/FOXR2 pathway which involved in regulating the permeability of glioma-conditioned normal blood-brain barrier [23]. These results suggested that IncRNA MIR17HG could be of pathogenic importance in the development and prognosis of glioma. Several previous studies have reported the effect of MIR17HG genetic polymorphisms on the risk of various disease including tumors [24, 25], but not in glioma.

Considering the importance of MIR17HG in the carcinogenic process of glioma, we hypothesized that MIR17HG polymorphisms might also are associated with glioma development. Here, we explored the relationship between five SNPs in MIR17HG and the risk and prognosis of glioma in a Chinese Han population. We found that rs7318578 might had a higher susceptibility to glioma. The incidence rates of glioma, that is, the rate of 
Table 6 Cox proportional hazards model of the association between MIR17HG variants and OS and PFS of glioma patients

\begin{tabular}{|c|c|c|c|c|c|c|c|c|c|}
\hline \multirow[t]{3}{*}{ SNP ID } & \multirow[t]{3}{*}{ Genotype } & \multicolumn{4}{|l|}{ Univariate } & \multicolumn{4}{|l|}{ Multivariate $^{a}$} \\
\hline & & \multicolumn{2}{|l|}{ OS } & \multicolumn{2}{|l|}{ PFS } & \multicolumn{2}{|l|}{ OS } & \multicolumn{2}{|l|}{ PFS } \\
\hline & & HR (95\% Cl) & $p$ & HR $(95 \% \mathrm{Cl})$ & $p$ & HR (95\% Cl) & $p$ & HR (95\% Cl) & $p$ \\
\hline \multicolumn{10}{|l|}{ Overall } \\
\hline \multirow[t]{3}{*}{ rs17735387 } & GG & 1 & & 1 & & 1 & & 1 & \\
\hline & GA & $0.85(0.70-1.03)$ & 0.097 & $0.83(0.69-1.01)$ & 0.059 & $0.84(0.69-1.01)$ & 0.067 & $0.82(0.68-0.99)$ & 0.042 \\
\hline & AA & $0.70(0.43-1.12)$ & 0.136 & $0.66(0.41-1.07)$ & 0.089 & $0.84(0.46-1.19)$ & 0.211 & $0.71(0.44-1.14)$ & 0.158 \\
\hline \multirow[t]{3}{*}{ rs72640334 } & $\mathrm{CC}$ & 1 & & 1 & & 1 & & 1 & \\
\hline & CA & $1.08(0.86-1.36)$ & 0.508 & $1.07(0.85-1.35)$ & 0.560 & $1.08(0.85-1.37)$ & 0.520 & $1.09(0.86-1.38)$ & 0.467 \\
\hline & AA & $1.56(0.74-3.29)$ & 0.247 & $1.44(0.68-3.05)$ & 0.335 & $1.25(0.58-2.66)$ & 0.569 & $1.20(0.56-2.56)$ & 0.633 \\
\hline \multirow[t]{3}{*}{ rs7318578 } & AA & 1 & & 1 & & 1 & & 1 & \\
\hline & $A C$ & $1.07(0.88-1.30)$ & 0.493 & $1.11(0.91-1.35)$ & 0.310 & 1.07 (0.88-1.30) & 0.516 & $1.10(0.90-1.34)$ & 0.353 \\
\hline & CC & $1.03(0.82-1.30)$ & 0.776 & $1.04(0.82-1.30)$ & 0.762 & $1.05(0.83-1.32)$ & 0.701 & $1.04(0.83-1.31)$ & 0.725 \\
\hline \multirow[t]{3}{*}{ rs7336610 } & $\pi$ & 1 & & 1 & & 1 & & 1 & \\
\hline & $\mathrm{TC}$ & $1.00(0.81-0.23)$ & 0.98 & $0.99(0.81-1.23)$ & 0.957 & $0.96(0.78-1.18)$ & 0.703 & $0.96(0.78-1.18)$ & 0.698 \\
\hline & CC & $0.93(0.72-1.19)$ & 0.549 & $0.89(0.69-1.15)$ & 0.381 & $0.91(0.71-1.17)$ & 0.480 & $0.89(0.69-1.15)$ & 0.375 \\
\hline \multirow[t]{3}{*}{ rs75267932 } & $A A$ & 1 & & 1 & & 1 & & 1 & \\
\hline & $A G$ & $1.07(0.85-1.33)$ & 0.585 & $1.07(0.85-1.34)$ & 0.568 & $1.04(0.83-1.31)$ & 0.727 & $1.05(0.84-1.32)$ & 0.671 \\
\hline & GG & $1.14(0.61-2.14)$ & 0.675 & $1.24(0.66-2.32)$ & 0.502 & $1.17(0.62-2.20)$ & 0.633 & $1.24(0.66-2.34)$ & 0.502 \\
\hline \multicolumn{10}{|c|}{ Low-grade glioma (I-II) } \\
\hline \multirow[t]{3}{*}{ rs17735387 } & GG & 1 & & 1 & & 1 & & 1 & \\
\hline & GA & $0.77(0.60-0.99)$ & 0.042 & $0.75(0.58-0.97)$ & 0.024 & $0.75(0.58-0.96)$ & 0.024 & $0.73(0.57-0.94)$ & 0.016 \\
\hline & AA & $0.64(0.36-1.15)$ & 0.138 & $0.62(0.35-1.11)$ & 0.110 & $0.68(0.38-1.22)$ & 0.195 & $0.70(0.39-1.26)$ & 0.233 \\
\hline \multicolumn{10}{|l|}{ Females } \\
\hline \multirow[t]{3}{*}{ rs72640334 } & $\mathrm{CC}$ & 1 & & 1 & & 1 & & & \\
\hline & $C A$ & $1.49(1.05-2.14)$ & 0.027 & $1.48(1.03-2.12)$ & 0.034 & $0.89(0.65-1.21)$ & 0.454 & $0.88(0.65-1.20)$ & 0.427 \\
\hline & AA & $1.50(0.66-3.38)$ & 0.332 & $1.35(0.60-3.05)$ & 0.470 & $2.05(0.28-4.87)$ & 0.477 & $2.62(0.36-8.99)$ & 0.342 \\
\hline \multicolumn{10}{|l|}{ Age $\geq \mathbf{4 0}$ years } \\
\hline \multirow[t]{3}{*}{ rs17735387 } & GG & 1 & & 1 & & 1 & & 1 & \\
\hline & GA & $1.30(1.00-1.68)$ & 0.500 & $0.80(0.62-1.04)$ & 0.098 & $0.77(0.59-1.00)$ & 0.047 & $0.79(0.61-1.03)$ & 0.084 \\
\hline & AA & $1.00(0.74-1.35)$ & 0.993 & $0.36(0.17-0.76)$ & 0.007 & $0.46(0.22-1.00)$ & 0.049 & $0.45(0.21-0.97)$ & 0.042 \\
\hline
\end{tabular}

Abbreviations: OS Overall survival, PFS Progression free survival, $H R$ Hazard ratio, $C I$ Confidence interval

${ }_{p} p$ values were calculated by Cox multivariate analysis with adjustments for gender, age, WHO grade, surgical method, use of radiotherapy and chemotherapy Bold $p<0.05$ indicates statistical significance

newly diagnosed tumor, are associated with increasing age and male gender [26]. We further analyzed whether the genotypic effects of MIR17HG on the risk of glioma were dependent on age and sex. We found that rs7318578 was related to the increase risk of glioma in the subjects with age $\geq 40$ years or in females. In addition, rs17735387 and rs7336610 also had a higher susceptibility to glioma in the subgroup aged $<40$ years. These indicated that the effect of MIR17HG polymorphisms on glioma occurrence might present age and sex difference. More importantly, we found that rs17735387 was related to the better prognosis of patients with glioma, particularly in low-grade glioma. Previously, rs7336610 was reported to be associated with the risk of multiple myeloma and breast cancer, while rs17735387 had no relationship with the risk and prognosis of multiple myeloma $[16,24]$. These results suggested that MIR17HG polymorphisms might have a different effect on the occurrence of different cancer types. However, our findings need further studies to confirm.

Inevitably, some limitations should not be ignored. First, all individuals including glioma patients and healthy controls were from the same hospital, therefore the selection bias cannot be ruled out. Second, due to the lack of data on environmental exposure and diet, the interaction between environment and genetics needs to be further explored in larger prospective studies. Third, the effect of 


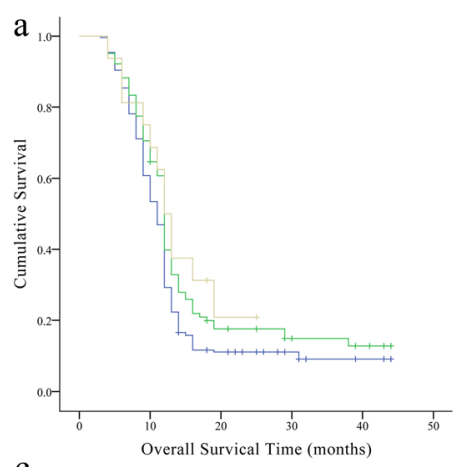

c

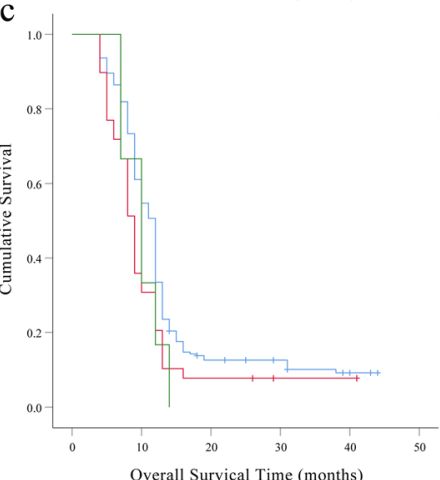

e

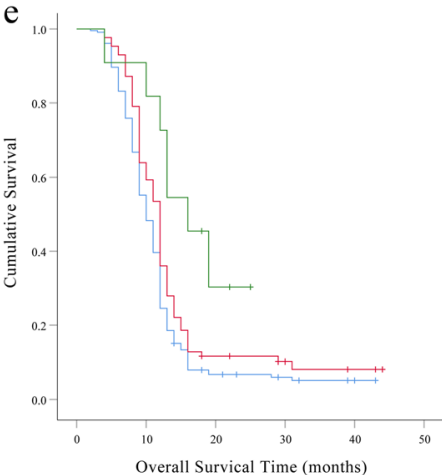

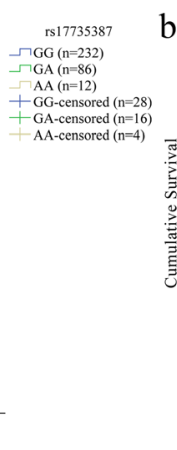

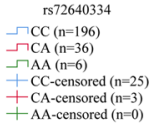

d
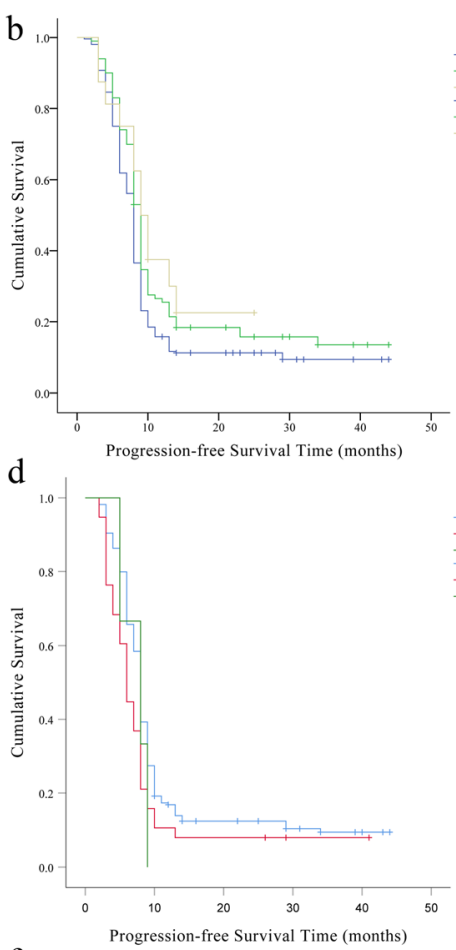

f
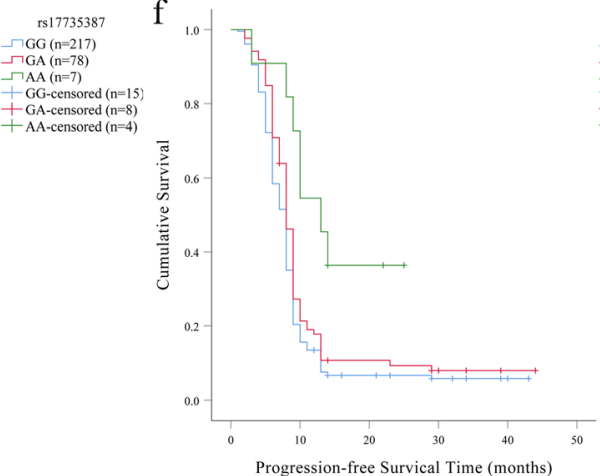

rs17735387

$\neg \mathrm{GG}(\mathrm{n}=232)$

$\mathrm{GA}(\mathrm{n}-84)$
$\mathrm{AA}(\mathrm{n}=12)$

GG-censored (n=28)
+ GA-ensored (n=16)
+ A

GA-censored ( $(\mathrm{n}=28)$
AA-censored $(\mathrm{n}=4)$ rs72640334

$\neg \mathrm{CC}(\mathrm{n}=195)$
$\neg \mathrm{CA}(\mathrm{n}=35)$

$\neg \mathrm{CA}(\mathrm{n}=35)$
$\neg \mathrm{AA}(\mathrm{n}=6)$

+ CC-censored (n=24)

+ CA-censored $(\mathrm{n}=3)$
+ AA-censored $(\mathrm{n}=0)$

Fig. 2 Stratified by age, sex and grade, effect of MIR17HG rs17735387 on the survival of patients. The survival curve of overall survival for patients with I-II glioma (a), female patients (c), patients with age $\geq 40$ years (e) and of progression free survival for patients with I-II glioma (b), female patients (d), patients with age $\geq 40$ years (f)

these SNPs on miR-17-92 cluster or lncRNA MIR17HG was not assessed.

\section{Conclusion}

In conclusion, we reported that MIR17HG rs7318578 might be a risk factor for the susceptibility of glioma and rs17735387 was associated with the longer survival of glioma among Chinese Han population. Our study firstly provided evidence about the effect of MIR17HG polymorphisms on the risk and prognosis of glioma, which might help to enhance the understanding of MIR17HG gene in gliomagenesis. In subsequent studies, we will continue to collect samples and follow up to further validate our findings and further explore the function of these MIR17HG SNPs in glioma in a larger sample size.

\section{Supplementary information}

Supplementary information accompanies this paper at https://doi.org/10. 1186/s12885-020-07417-9.

Additional file 1: Table S1. Primers sequence for PCR amplification and extension of MIR17HG variants. Table S2. The details of candidate SNPS in the MIRITHG gene.

\section{Abbreviations}

SNP: Single-nucleotide polymorphisms; OR: Odds ratio; Cl: Confidence intervals; HR: Hazard ratios; OS: Overall survival; PFS: Progression-free survival; MAFs: Minor allele frequencies; HWE: Hardy-weinberg equilibrium

Acknowledgements

We are grateful to the individuals for their participation in this study. 


\section{Authors' contributions}

The work presented here was carried out in collaboration between all authors. JF and YO carried out the molecular genetic studies and drafted the manuscript. DX designed the methods and experiments, performed the statistical analyses and interpreted the results. $\mathrm{QH}$ and $\mathrm{DL}$ designed primers and performed the SNP genotyping experiments. XF and PX collected clinical information about patients and performed the SNP genotyping experiments. YM conceived of the study, worked on associated data collection and their interpretation, participated in the design and coordination of the study, and funded the study. All authors read and approved the final manuscript.

\section{Funding}

This work was supported by 2016 Cultivation Fund of Hainan Medical College (HN2016-06) and 2019 Hainan Provincial Higher Education Scientific Research Project (Hnky2019-42).

\section{Availability of data and materials}

All the data regarding the findings are available within the manuscript. Anyone who is interested in the information should contact the corresponding author.

\section{Ethics approval and consent to participate}

Our research was approved by the Ethics Committee of the Second Affiliated Hospital of Hainan Medical University and was in the Declaration of Helsinki. Written informed consent was obtained from each participant.

\section{Consent for publication}

Not applicable.

\section{Competing interests}

The authors declare that they have no conflict of interest.

Received: 21 December 2019 Accepted: 15 September 2020

Published online: 09 October 2020

\section{References}

1. Weller M, Wick W, Aldape K, Brada M, Berger M, Pfister SM, et al. Glioma. Nat Rev Dis Primers. 2015;1:15017.

2. Chen W, Zheng R, Baade PD, Zhang S, Zeng H, Bray F, et al. Cancer statistics in China, 2015. CA Cancer J Clin. 2016;66:115-32.

3. Ostrom QT, Gittleman H, Stetson L, Virk S, Barnholtz-Sloan JS. Epidemiology of intracranial Gliomas. Prog Neurol Surg. 2018;30:1-11.

4. Chen $\mathrm{H}$, Chen Y, Zhao Y, Fan W, Zhou K, Liu Y, et al. Association of sequence variants on chromosomes 20,11, and 5 (20q13.33, 11q23.3, and 5 15.33) with glioma susceptibility in a Chinese population. Am J Epidemiol. 2011:173:915-22.

5. Wang D, Hu E, Wu P, Yuan W, Xu S, Sun Z, et al. Genetic variant near TERC influencing the risk of gliomas with older age at diagnosis in a Chinese population. J Neuro-Oncol. 2015;124:57-64.

6. Kinnersley B, Houlston RS, Bondy ML. Genome-wide association studies in Glioma. Cancer Epidemiol Biomark Prev. 2018;27:418-28.

7. Chen Y, Wu Y, Huang X, Qu P, Li G, Jin T, et al. Leukocyte telomere length: a novel biomarker to predict the prognosis of glioma patients. J Cancer Res Clin Oncol. 2015;141:1739-47.

8. Li S, Jin T, Zhang J, Lou H, Yang B, Li Y, et al. Polymorphisms of TREH, IL4R and CCDC26 genes associated with risk of glioma. Cancer Epidemiol. 2012;36:283-7.

9. Li G, Jin T, Liang H, Zhang Z, He S, Tu Y, et al. RTEL1 tagging SNPS and haplotypes were associated with glioma development. Diagn Pathol. 2013;8:83.

10. Olive V, Jiang I, He L. mir-17-92, a cluster of miRNAs in the midst of the cancer network. Int J Biochem Cell Biol. 2010;42:1348-54.

11. Molinari C, Salvi S, Foca F, Teodorani N, Saragoni L, Puccetti M, et al. miR-1792a-1 cluster host gene (MIR17HG) evaluation and response to neoadjuvant chemoradiotherapy in rectal cancer. OncoTargets Ther. 2016;9:2735-42.

12. Yuan J, Tan L, Yin Z, Zhu W, Tao K, Wang G, et al. MIR17HG-miR-18a/19a axis, regulated by interferon regulatory factor-1, promotes gastric cancer metastasis via Wnt/beta-catenin signalling. Cell Death Dis. 2019;10:454.

13. Mao JT, Xue B, Smoake J, Lu QY, Park H, Henning SM, et al. MicroRNA-19a/b mediates grape seed procyanidin extract-induced anti-neoplastic effects against lung cancer. J Nutr Biochem. 2016;34:118-25.
14. Cao S, Zheng J, Liu X, Liu Y, Ruan X, Ma J, et al. FXR1 promotes the malignant biological behavior of glioma cells via stabilizing MIR17HG. J Exp Clin Cancer Res. 2019;38:37.

15. Chen $P$, Bai $Y$, Li Y, Yuan Y, Cheng Y, Pang J, et al. Association between polymorphisms of MIR17HG and risk of colorectal cancer in the Chinese Han population. Mol Genet Genomic Med. 2019;7:e667.

16. Chacon-Cortes D, Smith RA, Lea RA, Youl PH, Griffiths LR. Association of microRNA 17-92 cluster host gene (MIR17HG) polymorphisms with breast cancer. Tumour Biol. 2015;36:5369-76.

17. Dobashi A, Tsuyama N, Asaka R, Togashi Y, Ueda K, Sakata S, et al. Frequent BCOR aberrations in extranodal NK/T-cell lymphoma, nasal type. Genes Chromosom Cancer. 2016;55:460-71.

18. Ellis JA, Ong B. The MassARRAY((R)) System for Targeted SNP Genotyping. Methods Mol Biol (Clifton, NJ). 2017;1492:77-94.

19. Sun G, SiMa G, Wu C, Fan Y, Tan Y, Wang Z. Decreased MiR-17 in glioma cells increased cell viability and migration by increasing the expression of Cyclin D1, p-Akt and Akt. PLoS One. 2018;13:e0190515.

20. Wang W, Zhang A, Hao Y, Wang G, Jia Z. The emerging role of miR-19 in glioma. J Cell Mol Med. 2018;22:4611-6.

21. Schulte $J H$, Marschall T, Martin M, Rosenstiel P, Mestdagh P, Schlierf S, et al. Deep sequencing reveals differential expression of microRNAs in favorable versus unfavorable neuroblastoma. Nucleic Acids Res. 2010;38:5919-28.

22. Cao Y, Wang P, Ning S, Xiao W, Xiao B, Li X. Identification of prognostic biomarkers in glioblastoma using a long non-coding RNA-mediated, competitive endogenous RNA network. Oncotarget. 2016;7:41737-47.

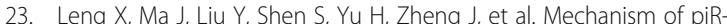
DQ590027/MIR17HG regulating the permeability of glioma conditioned normal BBB. J Exp Clin Cancer Res. 2018;37:246.

24. Wu H, Huang T, Ye Z, Fu X, Hu K, Yang X. Correlation of MicroRNA 17-92 cluster host gene (MIR17HG) polymorphisms with susceptibility and prognosis for multiple myeloma. Clin Lymphoma Myeloma Leuk. 2019;19:e359-e66.

25. Walther C, Mayrhofer M, Nilsson J, Hofvander J, Jonson T, Mandahl N, et al. Genetic heterogeneity in rhabdomyosarcoma revealed by SNP array analysis. Genes Chromosom Cancer. 2016;55:3-15.

26. Ostrom QT, Bauchet $\mathrm{L}$, Davis FG, Deltour I, Fisher JL, Langer CE, et al. The epidemiology of glioma in adults: a "state of the science" review. Neurooncology. 2014;16:896-913.

\section{Publisher's Note}

Springer Nature remains neutral with regard to jurisdictional claims in published maps and institutional affiliations.

Ready to submit your research? Choose BMC and benefit from:

- fast, convenient online submission

- thorough peer review by experienced researchers in your field

- rapid publication on acceptance

- support for research data, including large and complex data types

- gold Open Access which fosters wider collaboration and increased citations

- maximum visibility for your research: over $100 \mathrm{M}$ website views per year

At BMC, research is always in progress.

Learn more biomedcentral.com/submissions 